\title{
Comparative Impact of Voltage-Gated Calcium Channels and NMDA Receptors on Mitochondria-Mediated Neuronal Injury
}

\author{
Ruslan I. Stanika, Idalis Villanueva, Galina Kazanina, S. Brian Andrews, and Natalia B. Pivovarova \\ Laboratory of Neurobiology, National Institute of Neurological Disorders and Stroke, National Institutes of Health, Bethesda, Maryland 20892
}

Glutamate excitotoxicity, a major component of many neurodegenerative disorders, is characterized by excessive calcium influx selectively through NMDARs. However, there is a substantial uncertainty concerning why other known routes of significant calcium entry, in particular, VGCCs, are not similarly toxic. Here, we report that in the majority of neurons in rat hippocampal and cortical cultures, maximal L-type VGCC activation induces much lower calcium loading than toxic NMDAR activation. Consequently, few depolarizationactivated neurons exhibit calcium deregulation and cell death. Activation of alternative routes of calcium entry induced neuronal death in proportion to the degree of calcium loading. In a small subset of neurons, depolarization evoked stronger calcium elevations, approaching those induced by toxic NMDA. These neurons were characterized by elevated expression of VGCCs and enhanced voltage-gated calcium currents, mitochondrial dysfunction and cell death. Preventing VGCC-dependent mitochondrial calcium loading resulted in stronger cytoplasmic calcium elevations, whereas inhibiting mitochondrial calcium clearance accelerated mitochondrial depolarization. Both observations further implicate mitochondrial dysfunction in VGCC-mediated cell death. Results indicate that neuronal vulnerability tracks the extent of calcium loading but does not appear to depend explicitly on the route of calcium entry.

\section{Introduction}

Disruption of $\mathrm{Ca}^{2+}$ homeostasis is a critical event in neuronal degeneration following ischemic or traumatic brain injury (Greve and Zink, 2009; Szydlowska and Tymianski, 2010), as well as in several neurological disorders (Bezprozvanny, 2009). Under many pathological conditions, excessive glutamate release induces excitotoxicity, a condition that is characterized by massive $\mathrm{Ca}^{2+}$ influx mainly through NMDARs. Two major hypotheses that consider excessive intracellular $\mathrm{Ca}^{2+}$ as a trigger for neuronal death, namely, "calcium loading" (Hartley et al., 1993) and "source specificity" (Tymianski et al., 1993), have been debated for well over a decade. The first, inferred from the correlation between toxicity and the magnitude of the $\mathrm{Ca}^{2+}$ load, is in line with current models of excitotoxic cell death in which $\mathrm{Ca}^{2+}$ overload-induced mitochondrial dysfunction also plays a central role (for review, see Nicholls, 2009; Pivovarova and Andrews, 2010). On the other hand, there is considerable evidence for the idea that excitotoxic death is "source specific" because it is selectively linked to $\mathrm{Ca}^{2+}$ entry through NMDARs, most likely by a specialized mechanism that depends on activation of synaptic

Received Dec. 2, 2011; revised March 14, 2012; accepted March 20, 2012.

Author contributions: R.I.S., S.B.A., and N.B.P. designed research; R.I.S., I.V., G.K., and N.B.P. performed research; R.I.S., I.V., S.B.A., and N.B.P. analyzed data; R.I.S., S.B.A., and N.B.P. wrote the paper.

This research was supported by the Intramural Research Program of the NIH, NINDS. We are grateful to Christine A. Winters and Dr. Paul E. Gallant for excellent technical assistance.

Correspondence should be addressed to Natalia B. Pivovarova, 49/3A52, 49 Convent Drive, National Institutes of Health, Bethesda, MD 20892-4477. E-mail: PivovarN@ninds.nih.gov.

DOI:10.1523/JNEUROSCI.6008-11.2012

Copyright $\odot 2012$ the authors $\quad 0270-6474 / 12 / 326642-09 \$ 15.00 / 0$ neuronal nitric oxide synthase (nNOS) (Sattler et al., 1999; Aarts et al., 2002; Soriano et al., 2008).

From the viewpoint of the $\mathrm{Ca}^{2+}$ loading hypothesis, the prominent role of NMDARs in excitotoxic injury might reflect the fact that most other potential routes of $\mathrm{Ca}^{2+}$ entry generally restrict the amount of $\mathrm{Ca}^{2+}$ that can be transported (Hyrc et al., 1997; Stout and Reynolds, 1999). This view can explain why $\mathrm{Ca}^{2+}$ loading through AMPARs, for example, becomes strong and toxic only when their channels are rendered $\mathrm{Ca}^{2+}$ permeable (Carriedo et al., 2000), as well as why in hippocampal neurons vulnerability increases with age in parallel with VGCC expression and $\mathrm{Ca}^{2+}$ currents (Thibault et al., 2001; Brewer et al., 2007; Stanika et al., 2009). However, this straightforward hypothesis is not obviously consistent with certain results taken to support route specificity, for example, data showing that equivalent amounts of $\mathrm{Ca}^{2+}$ are highly toxic when loaded via NMDARs but not when loaded via VGCCs (Sattler et al., 1998; Aarts et al., 2002; Tymianski, 2009).

In the present study we provide evidence that loading a given amount of $\mathrm{Ca}^{2+}$ induces proportionate mitochondrial $\mathrm{Ca}^{2+} \mathrm{ac}^{2}$ cumulation and dysfunction regardless of the route of $\mathrm{Ca}^{2+}$ entry, and that this correlates with cell vulnerability. This principle explains the generally limited impact of VGCCs, since results show that in the majority of hippocampal neurons the $\mathrm{Ca}^{2+}$ load attainable via this route is much lower than that via NMDARs, and generally insufficient to induce mitochondrial dysfunction, nNOS activation, and cell death. However, in a small subset of neurons-one that becomes larger as cells age-VGCC activation does lead to $\mathrm{Ca}^{2+}$ loading approaching that induced by toxic NMDA, and also results in mitochondria-mediated cell death. 
These results support the proposition that differences in $\mathrm{Ca}^{2+}$ loading can adequately account for the privileged toxicity of NMDARs compared with VGCCs or other physiologically plausible pathways of $\mathrm{Ca}^{2+}$ entry.

\section{Materials and Methods}

Cell culture. Primary cultures of rat hippocampal and cortical neurons were prepared as previously described (Pivovarova et al., 2004). In brief, suspensions of a mixed population of brain cells prepared by papain dissociation of hippocampi or cortex from $\sim 20 \mathrm{~d}$ embryonic Sprague Dawley rats of either sex were plated onto previously prepared layers of glia in MEM supplemented with 5\% horse serum, $1 \%$ fetal bovine serum, 2 mм Glutamax (Life Technologies), $136 \mu \mathrm{M}$ uridine, $54 \mu \mathrm{M}$ 2-deoxy-5fluoro-uridine, and the growth factor cocktail N3. Cells were maintained in a $37^{\circ} \mathrm{C}$ incubator with $10 \% \mathrm{CO}_{2}$. Half of the culture medium was replaced twice weekly. All procedures, including animal euthanasia, were performed in accordance with an NINDS Animal Care and Use Committee Protocol. Experiments were performed on cultures 14-28 DIV.

Stimulation protocols, solutions, and viability assays. For experiments, cultures were transferred to a HEPES-buffered saline solution (HBSS) containing (in mM): $137 \mathrm{NaCl}, 10 \mathrm{HEPES}, 2.0 \mathrm{CaCl}_{2}, 1.0 \mathrm{MgSO}_{4}, 5.4 \mathrm{KCl}$, $0.3 \mathrm{Na}_{2} \mathrm{HPO}_{4}, 0.22 \mathrm{KH}_{2} \mathrm{PO}_{4}, 10$ glucose, and 26 sucrose ( $320 \mathrm{mOsM}, \mathrm{pH}$ 7.4). Maximal VGCC activation was performed according to published protocols (Sattler et al., 1998; Hardingham et al., 2002) by depolarizing the plasma membrane with a $\mathrm{Ca}^{2+}$-containing $(10 \mathrm{~mm})$ high $\mathrm{K}^{+}(90$ mM) solution (prepared by substituting $\mathrm{Na}^{+}$with $\mathrm{K}^{+}$) in HBSS in the presence of $10 \mu \mathrm{M}$ CNQX (an AMPAR blocker) and $20 \mu \mathrm{M}$ MK-801 (an NMDAR blocker), along with the L-type $\mathrm{Ca}^{2+}$-channel activators $(S)$ $(-)$-Bay K $8644(1 \mu \mathrm{M})$ or FPL $64176(5 \mu \mathrm{M})$. Excitotoxic activation of NMDARs was performed for $30 \mathrm{~min}$ in $\mathrm{Mg}^{2+}$-free HBSS containing 10 $\mu \mathrm{M}$ glycine and $100 \mu \mathrm{M}$ NMDA in the presence of $10 \mu \mathrm{M}$ nimodipine (an L-type VGCC blocker) and $10 \mu \mathrm{M}$ CNQX.

A modification of the protocol of Kiedrowski et al. (2004) was used to load $\mathrm{Ca}^{2+}$ via reverse mode $\mathrm{Na}^{+} / \mathrm{Ca}^{2+}$ exchange (NCX). Neurons were first incubated with $200 \mu \mathrm{M}$ glutamate and $1 \mathrm{~mm}$ ouabain in $\mathrm{Ca}^{2+}$-free $(2$ mM EGTA) HBSS for $20 \mathrm{~min}$ to $\mathrm{Na}^{+}$load cells, followed by brief exposure to $20 \mu \mathrm{M}$ MK-801 (to block NMDARs) before reintroduction of $\mathrm{Ca}^{2+}$ (10 mM in HBSS in the presence of MK-801) to activate NCX. A "chemical LTD" protocol that degrades PSDs, thereby unlinking NMDARs from nNOS and preventing synaptic nNOS activation (Colledge et al., 2003; Di Biase et al., 2008), consisted of a brief exposure ( $5 \mathrm{~min}$ ) to $100 \mu \mathrm{M}$ NMDA.

For viability assays, cultures after stimulation were washed in HBSS and returned to the incubator in growth medium for 20-24 h. Cell death was assayed by propidium iodide $(3.3 \mu \mathrm{g} / \mathrm{ml})$ staining. Immunostaining for NeuN, a neuron-specific protein, was used to assay the total number of neurons. Cell counting was performed using ImageJ software (http://rsb.info.nih.gov/ij/index.html).

Nimodipine, CNQX, MK-801, ( S)-(-)-Bay K 8644, FPL 64176, ionomycin, and CGP 37157 were purchased from Tocris Bioscience and NeuN from Millipore Bioscience Research Reagents. All other reagents were from Sigma-Aldrich.

Fluorescence microscopy. Intracellular cytosolic free $\mathrm{Ca}^{2+}$ concentrations were estimated using the low-affinity $\mathrm{Ca}^{2+}$ probe fura- $2 \mathrm{FF}$ (TEFLabs). For dye loading, cultures were incubated in $4 \mu \mathrm{M}$ fura-2FF AM in HBSS for 30 min at $37^{\circ} \mathrm{C}$ and subsequently imaged using a Zeiss Axiovert 200 light microscope equipped with a $40 \times$ objective. Images were recorded by means of a CoolSNAP HQ2 CCD camera (Photometrics) controlled by EasyRatioPro software (Photon Technology International). All experiments were performed at $25^{\circ} \mathrm{C}$. For quantitative imaging, fura-2FF was excited alternately at 340 and $380 \mathrm{~nm}$ and fluorescence emission was collected at $510 \mathrm{~nm}$. $\mathrm{Ca}^{2+}$ concentrations were quantified from the ratio of 340/380 fluorescence intensities using established methods (Grynkiewicz et al., 1985). During imaging, cultures were continuously perfused with HBSS containing added drugs as needed. Images were collected at 5-30 s intervals during the initial part of the experiment and at $60 \mathrm{~s}$ intervals during the final part. Due to the inherent uncertainties of calibration procedures, absolute concentrations should be considered as estimates.
Mitochondrial membrane potentials (MMPs) were visualized with the membrane-permeant cationic dye rhodamine-123 (Rh123) (Invitrogen; excitation $514 \mathrm{~nm}$, emission $530 \mathrm{~nm}$ ). Cultures were incubated for 15 min at $37^{\circ} \mathrm{C}$ in $25 \mu \mathrm{M}$ Rh123 in HBSS and washed an additional 15 min before imaging. Rh123 is accumulated and quenched in polarized mitochondria; upon depolarization, the dye is released from mitochondria leading to increased cytosolic fluorescence in proportion to the degree of depolarization. Intracellular nitric oxide (NO) production was assayed using DAF-FM diacetate (4-amino-5-methylamino-2', $7^{\prime}$-difluorofluorescein diacetate, Invitrogen; excitation $488 \mathrm{~nm}$, emission $505 \mathrm{~nm}$ ) (Marks et al., 2005). Cultures were incubated with $10 \mu \mathrm{M}$ DAF-FM in HBSS for $30 \mathrm{~min}$ at $37^{\circ} \mathrm{C}$ and washed for $15 \mathrm{~min}$. Imaging of Rh123 and DAF-FM was performed at room temperature using a Zeiss LSM 510 confocal microscope equipped with a $40 \times$ objective.

Immunocytochemistry. Cells were fixed for $10 \mathrm{~min}$ at $-20^{\circ} \mathrm{C}$ with methanol, then washed three times with PBS and permeabilized with $0.5 \%$ Triton X-100 in blocking solution (2\% BSA, 2\% NGS in PBS) for $1 \mathrm{~h}$. Immunostaining was performed using a rabbit primary antibody against the $\alpha 1 \mathrm{C}$ subunit of the L-type $\left(\mathrm{Ca}_{\mathrm{v}} 1.2\right)$ calcium channel (1:200, Sigma-Aldrich). Cultures were incubated with primary antibodies at room temperature for $1 \mathrm{~h}$ and after washing were stained with secondary goat anti-rabbit IgG FITC-conjugated antibodies (1:500, Millipore Bioscience Research Reagents) at room temperature for $2 \mathrm{~h}$.

Electrophysiology. Cells were voltage-clamped in whole-cell configuration. Calcium channel activity was recorded by $2-4 \mathrm{M} \Omega$ micropipettes manufactured from borosilicate glass capillary tubes with micropipette puller P-87 (Sutter Instruments). Cells were depolarized from a holding potential of $-70 \mathrm{mV}$ to $+10 \mathrm{mV}$ with $20 \mathrm{mV}$ steps, and recordings were filtered at $5 \mathrm{kHz}$, digitized at $10 \mathrm{kHz}$ using an Axopatch 200B amplifier, and integrated with a Digidata 1440A data acquisition system (Molecular Devices). The composition of the external solution was as follows (in $\mathrm{mM}$ ): 25 tetraethylammonium chloride, 5 4-aminopyridine, $2 \mathrm{MgCl}_{2}, 3$ $\mathrm{KCl}, 5 \mathrm{CaCl}_{2}, 20 \mathrm{HEPES}, 100 \mathrm{NaCl}, 0.001 \mathrm{TTX}$, at pH 7.4. Pipette solution was (in mM): $56 \mathrm{CsCl}, 47 \mathrm{Cs}_{2} \mathrm{SO}_{4}, 20$ HEPES, $1 \mathrm{MgCl}_{2}, 4 \mathrm{ATP}, 0.3$ GTP, 0.5 EGTA, $0.2 \mathrm{CaCl}_{2}$, pH 7.2.

Electron microscopy and electron probe $x$-ray microanalysis. For electron microscopy and electron probe $\mathrm{x}$-ray microanalysis (EPMA), cultures were rapidly frozen, cryosectioned, imaged, and analyzed in an analytical electron microscope as previously described (Pivovarova et al., 2004). $\mathrm{X}$-ray spectra were recorded and processed by established procedures (Pivovarova et al., 1999), providing total concentrations of cytoplasmic and mitochondrial $\mathrm{Ca}, \mathrm{Na}, \mathrm{Mg}, \mathrm{P}, \mathrm{Cl}$, and $\mathrm{K}$ in units of $\mathrm{mmol} / \mathrm{kg}$ dry weight.

Statistics. One-way ANOVA followed by post hoc Dunnett's multiplecomparisons test was used for normally distributed data. For nonnormally distributed data the nonparametric Kruskal-Wallis rank ANOVA with post hoc Dunn's test was used. Data are given as mean \pm SEM. Analysis was performed using InStat software (GraphPad Software). In general, experiments were performed on at least three cultures prepared from different animals.

\section{Results}

\section{Neuronal vulnerability parallels cytosolic $\mathrm{Ca}^{2+}$ elevations}

We first compared the elevation of cytoplasmic free $\mathrm{Ca}^{2+}$ induced by activation of VGCCs and NMDARs in cultured rat hippocampal and cortical neurons using the low-affinity $\mathrm{Ca}^{2+}$ probe fura-2FF. VGCCs were activated by strong depolarization according to published protocols that used $90 \mathrm{mM} \mathrm{K}^{+}$together with the VGCC activator Bay K 8644 in $10 \mathrm{mM} \mathrm{Ca}^{2+}$-containing saline (Sattler et al., 1998) to maximize $\mathrm{Ca}^{2+}$ influx. The majority of 14 DIV cells exhibited a typical $\mathrm{Ca}^{2+}$ spike, followed by decay to a steady-state level slightly higher than basal concentrations (Fig. 1A); a small subset of cells (whose significance is discussed below) maintained much higher $\mathrm{Ca}^{2+}$ levels, $>5 \mu \mathrm{M}$ (Fig. $1 \mathrm{~A}$ ). The average $\mathrm{Ca}^{2+}$ concentration after high $\mathrm{K}^{+}$exposure was $\sim 4$ $\mu \mathrm{M}$ (Fig. 1A,C). Replacement of Bay K 8644 with FPL 64176 (Hardingham et al., 2002) produced similar results (data not 


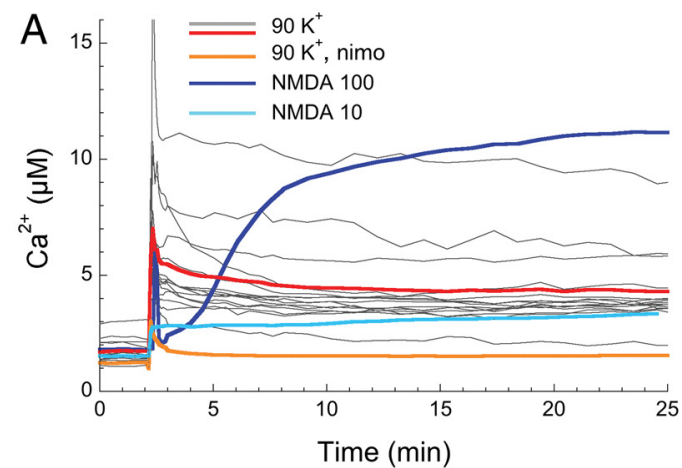

C
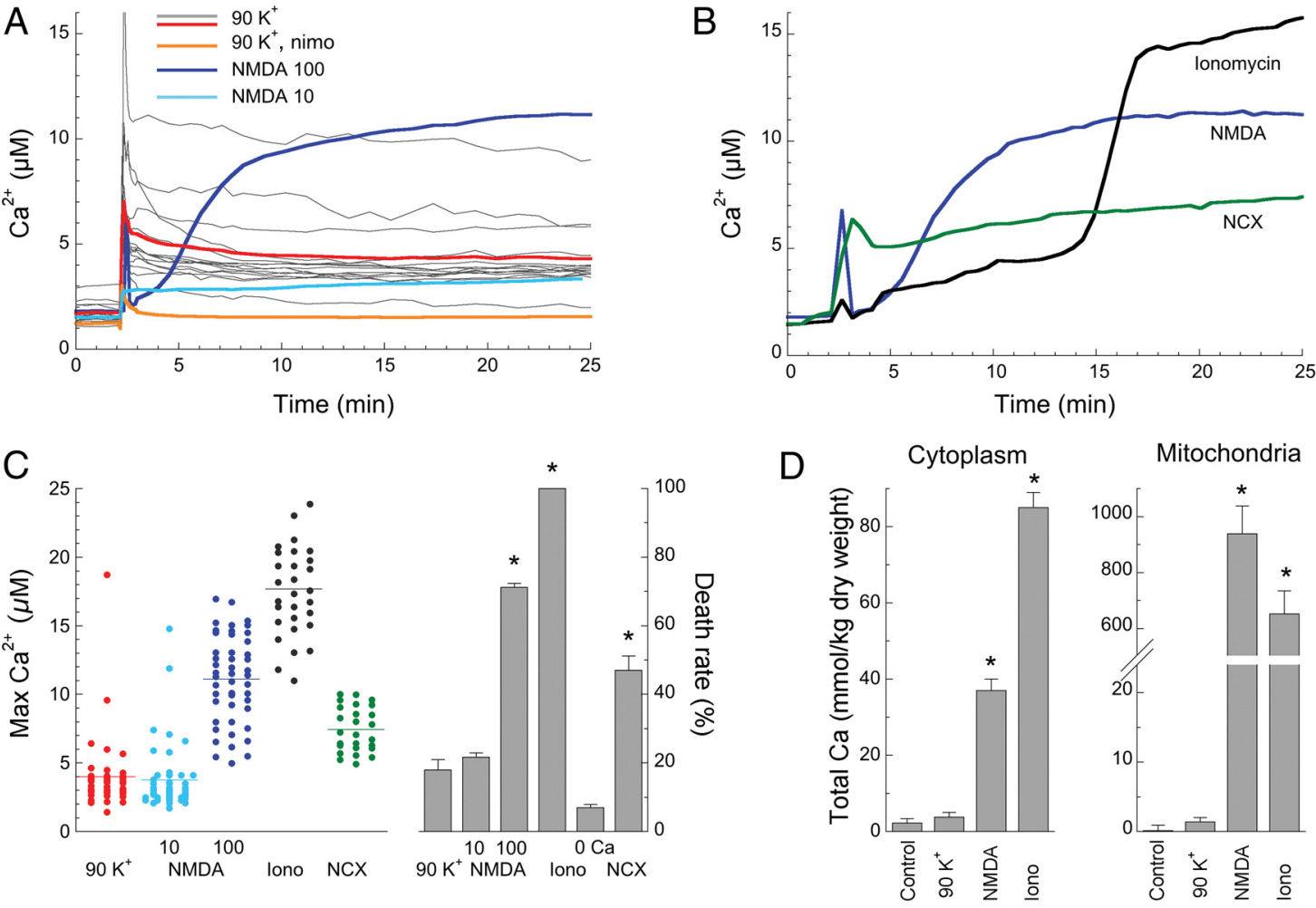

D
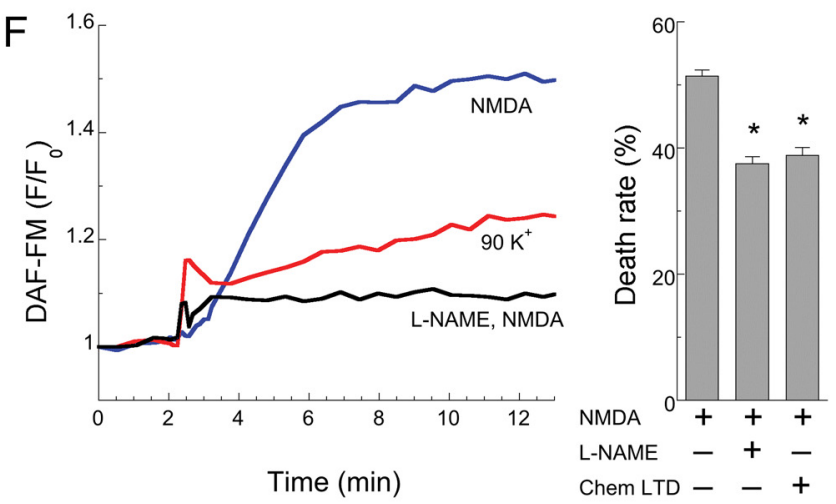

Figure 1. Strong VGCC activation induces lower $\mathrm{Ca}^{2+}$ elevations and less death than NMDAR activation. $\boldsymbol{A}$, Time course of $90 \mathrm{~mm} \mathrm{~K}^{+}$-induced free Ca ${ }^{2+}$ elevations (fura-2FF) in individual 14 DIV

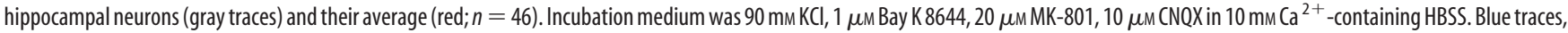
Average $\mathrm{Ca}^{2+}$ elevations induced by $100 \mu \mathrm{m}$ (dark blue; $\left.n=49\right)$ and $10 \mu \mathrm{m}$ (light blue; $\left.n=47\right)$ NMDA. Orange trace, Average Ca ${ }^{2+}$ response induced by high $\mathrm{K}^{+}$in the presence of $10 \mu \mathrm{m}$ nimodipine $(n=35)$. $\boldsymbol{B}$, Representative $\mathrm{Ca}^{2+}$ traces from experiments in which $\mathrm{Ca}^{2+}$ entry was induced by $100 \mu \mathrm{M}$ NMDA (as in $\left.\boldsymbol{A}\right), 10 \mu \mathrm{m}$ ionomycin (lono, $\left.n=30\right)$, or reverse mode NCX $(n=$ 40; see Materials and Methods for protocol). $\boldsymbol{C}$, Left, Maximal sustained concentration of free $\mathrm{Ca}^{2+}$ in individual neurons 30 min after the activation of $\left(\mathrm{a}^{2+}\right.$ uptake as in $\boldsymbol{A}$ and $\left.\boldsymbol{B}\right)$. Right, Neuronal death rate $24 \mathrm{~h}$ after the same stimuli. No significant cell death was observed in controls without stimulation. $D$, Concentrations of total calcium in the cytoplasm and mitochondria of neurons immediately after 30 min of stimulation as described in $\boldsymbol{A}$ and $\boldsymbol{B}$. Data are mean $\pm \mathrm{SEM}$, as measured by EPMA. $\boldsymbol{E}$, Time courses of Rh123 relative fluorescence $\left(F / F_{0}\right)$ show no significant changes of MMP in 14 DIV hippocampal neurons induced by $90 \mathrm{~K}^{+}$depolarization $(n=23)$ and typical strong MMP depolarization induced by NMDA (100 $\mu$ M; $\left.n=26\right)$. $\boldsymbol{F}$, Left, Representative traces of N0 production (DAF-FM fluorescence; F/F $)$ induced by $100 \mu \mathrm{M} \mathrm{NMDA}(n=19)$ alone or in the presence $100 \mu \mathrm{m} \mathrm{L-NAME}(n=14)$, or by 90 mm K ${ }^{+}$depolarization $(n=16)$. Right, Neuronal death rate $24 \mathrm{~h}$ after NMDA stimulation is reduced by pharmacological NOS inhibition (L-NAME) or by disrupting the NMDAR/nNOS linkage using a chemical LTD protocol (see Materials and Methods).

shown). Depolarization-induced $\mathrm{Ca}^{2+}$ elevations were blocked by the L-type VGCC blocker nimodipine (Fig. $1 A$ ) but were unaffected by the N/P-type $\mathrm{Ca}^{2+}$ channel blocker $\omega$-conotoxin MVIIC (data not shown), indicating that $\mathrm{Ca}^{2+}$ influx was mainly mediated by L-type VGCCs.

In contrast to VGCC activation, exposure to excitotoxic NMDA induced strong, biphasic cytosolic $\mathrm{Ca}^{2+}$ increases in essentially all neurons, the second phase representing complete $\mathrm{Ca}^{2+}$ deregulation with average $\mathrm{Ca}^{2+}$ concentrations $>10 \mu \mathrm{M}$ (Fig. 1 $A, C$ ). Typical traces were similar to previous records from ourselves and others (Abramov and Duchen, 2008; Li et al., 2009; Stanika et al., 2009). VGCC and NMDAR activation in 14 DIV cortical neurons produced similar results (data not shown). Importantly, the size and distribution of the $\mathrm{Ca}^{2+}$ elevations induced by these two diverse stimuli (Fig. $1 C$, left) correlate well with cell viability (Fig. $1 C$, right). Thus, VGCC activation resulted in the death of only $\sim 20 \%$ of neurons in 14 DIV cultures, whereas NMDAR activation led to massive delayed neuronal death, $\sim 70 \%$ (Fig. $1 C$, right).

Several additional approaches were used to further test the idea that the size of the $\mathrm{Ca}^{2+}$ load is a dominant factor governing neuronal vulnerability. First, NMDA concentrations were incrementally adjusted downward, progressively reducing $\mathrm{Ca}^{2+}$ elevations and death rates until, at $10 \mu \mathrm{M}$ NMDA, they were essentially 
equal to the lower $\mathrm{Ca}^{2+}$ elevations $(\sim 4 \mu \mathrm{M})$ and death rates $(\sim 20 \%)$ induced by maximal $90 \mathrm{~mm} \mathrm{~K}^{+}$depolarization (Fig. 1C). Conversely, exposure to the $\mathrm{Ca}^{2+}$ ionophore ionomycin (10 $\mu \mathrm{M}$ ), which leads to strong $\mathrm{Ca}^{2+}$ accumulation by an entirely different route, resulted in cytosolic $\mathrm{Ca}^{2+}$ levels even higher than toxic NMDA, in parallel with a proportionately higher death rate (Fig. $1 \mathrm{~B}, C$ ); in contrast, ionomycin exposure in $\mathrm{Ca}^{2+}$-free medium was entirely nontoxic (Fig. 1C). Finally, an intermediate regime of $\mathrm{Ca}^{2+}$ loading was achieved by exploiting mechanisms that depend on reversal of the plasma membrane NCX. Cells were $\mathrm{Na}^{+}$loaded by global glutamate receptor activation in a $\mathrm{Ca}^{2+}{ }_{-}$ free medium, followed by MK-801 block of activated NMDARs and reintroduction of extracellular $\mathrm{Ca}^{2+}$ to activate NCX in reverse mode (Kiedrowski et al., 2004). This protocol leads, as expected, to intermediate levels of $\mathrm{Ca}^{2+}$ elevation and corresponding cell death (Fig. $1 B, C$ ).

\section{Cytosolic and mitochondrial total calcium loading}

Although small free cytosolic $\mathrm{Ca}^{2+}$ elevations imply limited calcium uptake, and vice versa, it is important to evaluate total calcium loading directly because the calcium loading hypothesis holds that cell death is triggered by excessive amounts of total intracellular calcium (Hartley et al., 1993). Thus, we used electron probe $\mathrm{x}$-ray microanalysis (EPMA) to show that cytosolic total calcium concentrations closely follow the same trend as free $\mathrm{Ca}^{2+}$ elevations and death rates, namely, that toxic NMDA and ionomycin strongly load cells with calcium $(37 \pm 3$ and $91 \pm 4$ $\mathrm{mmol} / \mathrm{kg}$ dry weight, respectively), while even maximal VGCC induces minimal calcium accumulation in the majority of cells $(3.8 \pm 1.2 \mathrm{mmol} / \mathrm{kg}$ ) (Fig. $1 D$, left). Significantly, mitochondrial calcium loading after NMDA, ionomycin, or $90 \mathrm{~mm} \mathrm{~K}^{+}$exposure $-938 \pm 110,652 \pm 83$ and $1.4 \pm 0.6 \mathrm{mmol} / \mathrm{kg}$, respectively (Fig. $1 D$, right) — tracked cytosolic changes. As would be predicted by such large differences in mitochondrial calcium accumulation, strong VGCC activation, unlike toxic NMDAR activation, did not induce detectable mitochondrial depolarization (Fig. $1 E$ ). To summarize, all measures-free $\mathrm{Ca}^{2+}$, total calcium, mitochondrial calcium, mitochondrial depolarization-support the proposition that neuronal death rates closely parallel cell and mitochondrial calcium loading. In the specific case of VGCCs, even excessively strong activation is not toxic because calcium loading in the large majority of neurons is low and insufficient to trigger mitochondrial dysfunction and cell death.

\section{The role of nitric oxide}

Although we consider the evidence presented so far as strong support for the calcium loading hypothesis of excitotoxic injury, it leaves unanswered questions about how calcium loading relates to the well documented source specificity hypothesis. Calcium activation of synaptic nNOS, a PSD-95-linked component of the postsynaptic density (PSD), is thought to underlie the selective toxicity of $\mathrm{Ca}^{2+}$ entry through NMDARs (Forder and Tymianski, 2009). Although the focus of this hypothesis is fundamentally different from the calcium loading hypothesis, the two are not necessarily incompatible-a view supported by the role of nNOS activation in our cells. As shown in Figure $1 F$, toxic NMDA significantly increased NO levels (as reported by the NO-specific probe DAF; Marks et al., 2005), while NOS inhibition with L-NAME prevented NMDA-induced NO production and reduced cell death by $\sim 25 \%$. Moreover, synaptic nNOS appears to be the major contributor to NO production since disrupting PSDs using a chemical LTD strategy (see Materials and Methods for protocol) (Colledge et al., 2003; Di Biase et al., 2008) similarly reduced NMDA toxicity (Fig. $1 F$ ). As might be expected because depolarization induces minimal $\mathrm{Ca}^{2+}$ loading, VGCC activation did not induce significant NO production. These observations are compatible with both source specificity and calcium loading.

\section{Calcium-dependent injury in older neurons}

The developmental program of hippocampal neurons in culture provides additional opportunities to dissect out VGCC-dependent contributions to neuronal injury. To be specific, VGCCactivated $\mathrm{Ca}^{2+}$ influx increases during aging (Thibault and Landfield, 1996; Thibault et al., 2001), as well as in older cells in culture (Stanika et al., 2009). This leads to the expectation that any VGCC-dependent component of neuronal vulnerability should be enhanced as a result of increased $\mathrm{Ca}^{2+}$ elevations in older cells. We confirmed that under our culture conditions older hippocampal neurons (28 DIV) express significantly more functional L-type VGCCs than do 14 DIV cells (Fig. 2A), and that this difference is reflected in considerably larger voltage-activated $\mathrm{Ca}^{2+}$ currents (Fig. 2B). Also in contrast to 14 DIV cells, VGCC activation of older cells resulted in stronger $\mathrm{Ca}^{2+}$ elevations in a larger fraction of neurons, some of these cells exhibiting $\mathrm{Ca}^{2+}$ levels approaching those induced by NMDA (Fig. 2C,D; compare Fig. $1 A, C$ ). The larger fraction of $28 \mathrm{DIV}$ cells with elevated $\mathrm{Ca}^{2+}$ was paralleled by a larger death rate, $\sim 30 \%$ (Fig. $2 D$, right), which is consistent with the correlation seen in 14 DIV cells. Both depolarization-induced $\mathrm{Ca}^{2+}$ elevations (data not shown) and neuronal death $(25 \pm 2 \%$ vs $6 \pm 1 \%, p<0.001)$ were prevented by nimodipine.

\section{VGCC-mediated calcium loading and mitochondrial dysfunction}

The general correlation between calcium loading and cell death (cf. Fig. 1C) is reminiscent of the well established link between glutamate-induced, calcium overload-dependent mitochondrial dysfunction and excitotoxic death (Nicholls, 2009). This raises the question as to whether VGCC-mediated injury is mechanistically analogous. Twenty-eight DIV cultures enriched in vulnerable cells were used to test whether $\mathrm{Ca}^{2+}$ entering via VGCCs can accumulate in and damage mitochondria. In a first approach, these cells were pretreated before VGCC activation with the protonophore FCCP (carbonyl cyanide 4-(trifluoromethoxy)phenylhydrazone), which depolarizes mitochondria and thus prevents mitochondrial calcium accumulation (Stout et al., 1998). This pretreatment strongly enhanced depolarization-induced cytosolic $\mathrm{Ca}^{2+}$ elevations so that they became quite large in a subset of cells (Fig. $3 A$ ). This response indicates that much of the $\mathrm{Ca}^{2+}$ entering through VGCCs is sequestered in mitochondria.

Electron microscopy provided further evidence that VGCCmediated $\mathrm{Ca}^{2+}$ loading can damage mitochondria. As discussed previously (Pivovarova and Andrews, 2010), NMDA-mediated mitochondrial $\mathrm{Ca}^{2+}$ overload is generally accompanied by dramatic structural changes, including massive mitochondrial swelling and the formation of calcium-rich inclusions within mitochondrial matrices (see, for example, Fig. 3B, bottom). These changes in mitochondrial structure have proven to be a diagnostically useful predictor of delayed cell death (Pivovarova et al., 2008). In contrast to cells exposed to NMDA, the majority of strongly depolarized neurons maintained normal mitochondrial morphology (Fig. 3B, top), consistent with limited mitochondrial calcium accumulation. However, a fraction of cells similar in size to the previously mentioned minor subset with elevated cytosolic $\mathrm{Ca}^{2+}$ contained a large number of swollen, damaged, 
and inclusion-containing mitochondria (Fig. 3B, middle). Thus, structural observations suggest that, even though depolarization-induced mitochondrial calcium loads do not in general exceed the mitochondrion's loading capacity, $\mathrm{Ca}^{2+}$ entry through VGCCs is capable of triggering mitochondrial damage in those cases where entry is unusually strong.

The evident difference in cell-to-cell structural responses to depolarization allowed cells to be partitioned into two objectively defined subsets: (1) a dominant subset displaying normal subcellular ultrastructure (Fig. 3B, top); and (2) a second, minor subset containing abundant swollen, structurally damaged mitochondria (Fig. 3B, middle). As a measure of the large structural differences between members of these subsets, the average cross-sectional area of mitochondria in the dominant population was $0.164 \pm 0.007$ (SD) $\mu \mathrm{m}^{2}$, compared with $0.611 \pm 0.053 \mu \mathrm{m}^{2}(p<$ 0.001 ) in the minor population.

An additional, complementary approach examined the effect of VGCCdependent calcium loading on the MMP. It is well established (Schinder et al., 1996; Vergun et al., 1999) that toxic NMDAR activation of hippocampal neurons leads to strong MMP depolarization. In contrast, we found that VGCC activation had almost no effect on the MMP in the majority of 14 DIV neurons (Fig. 1 E), but did induce a delayed increase of Rh123 fluorescence in a subset $(\sim 30 \%)$ of 28 DIV neurons (Fig. $4 A$ ) whose size matches the death rate under these conditions (Fig. 2D). When mitochondrial overload was accelerated by blocking mitochondrial $\mathrm{Ca}^{2+}$ release with CGP 37157, an inhibitor of the mitochondrial $\mathrm{Na}^{+} / \mathrm{Ca}^{2+}$ exchanger, the delayed onset of depolarization was significantly shortened (Fig. 4B).

As a final and direct test of whether mitochondria can accumulate damaging amounts of calcium that enter through VGCCs, EPMA was used to measure and compare NMDA- and depolarization-induced changes in total calcium loading in 28 DIV cells. Strong depolarization led to only a slight increase in cytoplasmic total calcium in the dominant population of cells (Table 1, Row 1 vs Row 2); this increase was much lower than the total cytoplasmic calcium elevations induced by excitotoxic NMDA (Table 1, Row 4), but reminiscent of the generally small depolarization-induced increases in free cytosolic $\mathrm{Ca}^{2+}$. Consistent with the variability of the free $\mathrm{Ca}^{2+}$ response to depolarization (Fig. 1A), neurons of the minor subset characterized by severely damaged mitochondria, and only these neurons, exhibited strongly elevated cytoplasmic total calcium (Table 1, Row 3).

Mitochondria in the dominant subset of cells accumulated little calcium following depolarization (Table 1, Row 5 vs Row 6), which is consistent with the small elevations in cytoplasmic calcium. Thus, the calcium content of the structurally normal cells of this population clustered around relatively low concentrations (Fig. 5A, open circles). However, in the minor subset with elevated cytoplasmic calcium, the concentration of mitochondrial
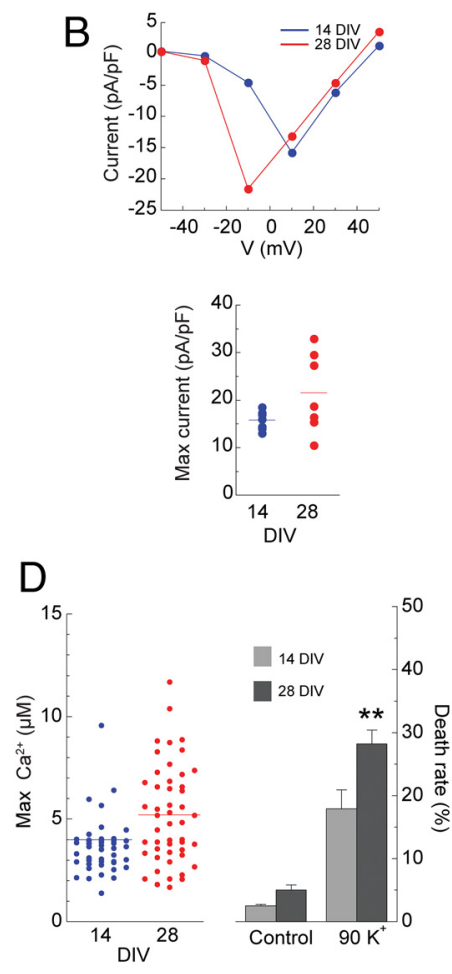

Figure 2. VGCC expression and activity are increased in older neurons. $\boldsymbol{A}$, Confocal images of hippocampal neurons - fixed at 14 $\mathrm{mV}$ steps. C, Time course of free $\mathrm{Ca}^{2+}$ elevations after $90 \mathrm{~mm} \mathrm{~K}^{+}$depolarization (as in Fig. 1) in individual 28 DIV hippocampal same age $(n=26)$. $\boldsymbol{D}$, Maximal sustained concentration of free $\mathrm{Ca}^{2+}$ in individual neurons after $90 \mathrm{~mm} \mathrm{~K}^{+}$depolarization in

calcium was strongly increased (Fig. $5 A$, filled circles), approaching that induced by NMDA (Fig. $5 B$; Table 1, Row 7 vs Row 8). The punctate, heterogeneous distribution of calcium within these mitochondria resembled that typically observed after strong mitochondrial calcium loading (compare Fig. $3 B$, middle vs bottom) (Pivovarova et al., 2004; Kristian et al., 2007). Importantly, there was a linear correlation between cytoplasmic and mitochondrial calcium concentrations in neurons of the minor subset (Fig. 5A, filled circles). In summary, structural, functional, and analytical data support the conclusion that VGCC-mediated $\mathrm{Ca}^{2+}$ entry is fully capable of inducing mitochondrial dysfunction, but generally does not do so because the mitochondrial calcium load, limited by the relatively low $\mathrm{Ca}^{2+}$ permeability of L-type VGCCs, is too small.

\section{A role for sodium in VGCC-mediated injury?}

In addition to $\mathrm{Ca}^{2+}$ overload, there is clear evidence that neuronal vulnerability to NMDA is influenced by changes in the cytosolic concentrations of other ions, $\mathrm{Na}^{+}$being particularly important. Elevated cytosolic $\mathrm{Na}^{+}$increases $\mathrm{Na}^{+} / \mathrm{K}^{+}$-ATPase pump activity, thereby creating an additional ATP demand. In some circumstances this will lead to energy deficiency, which in turn will exacerbate mitochondrial dysfunction and enhance neuronal death (Nicholls, 2008). Thus, elevated $\mathrm{Na}^{+}$might represent an additive factor that raises vulnerability to NMDAR activation. However, EPMA measurements in our cells show that in contrast to the effects of NMDA, which reverses the normal in- 

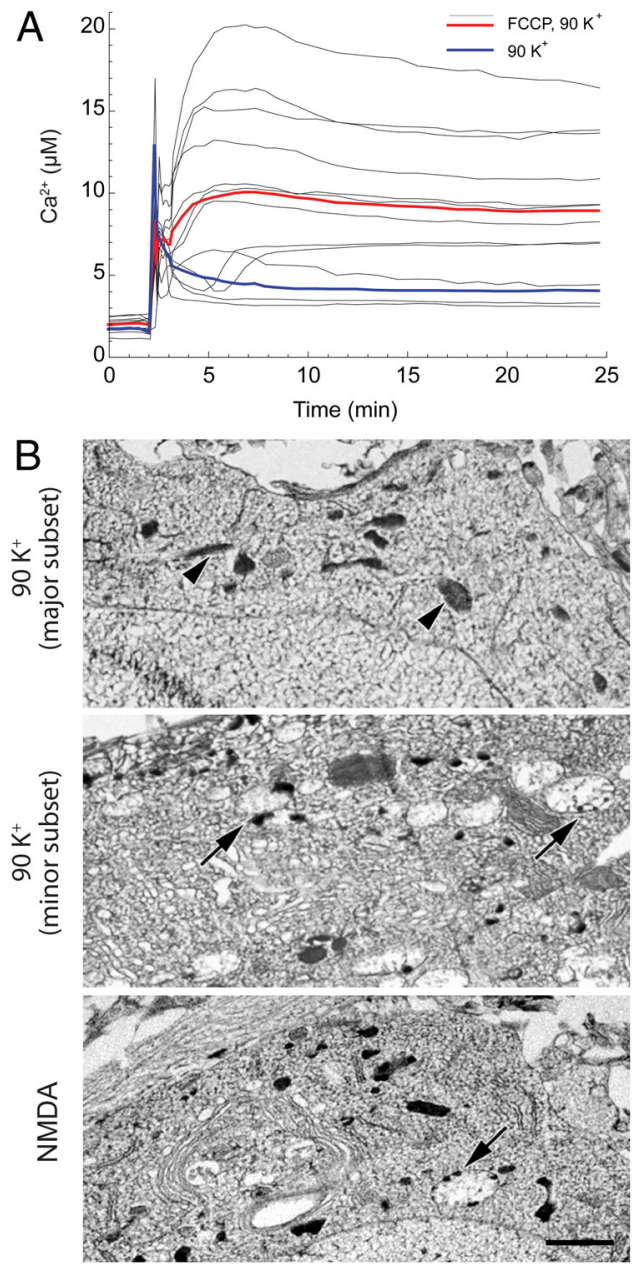

Figure 3. VGCC-mediated calcium overload and mitochondrial structural damage. $A$, In neurons pretreated with $\mathrm{FCCP}(1 \mu \mathrm{m})$ to eliminate mitochondrial calcium accumulation, $90 \mathrm{~mm} \mathrm{~K}^{+}$ depolarization (as described in Fig. 1) leads to rapid cytosolic $\mathrm{Ca}^{2+}$ deregulation $(\sim 10 \mu \mathrm{M})$ in 28 DIV neurons. Bold traces are the averages from representative coverslips for $90 \mathrm{~mm} \mathrm{~K}$ depolarization with ( $n=12$ ) or without ( $n=14)$ FCCP. $B$, Electron micrographs of freeze-dried cryosections prepared from 28 DIV cultured hippocampal neurons rapidly frozen immediately after 30 min exposure to $90 \mathrm{~mm} \mathrm{~K}^{+}$(as in Fig. 1) or $100 \mu \mathrm{m}$ NMDA. Top, Cell body with normal mitochondrial structure (arrowheads). Image is representative of the dominant population of depolarized neurons. Middle, Cell body with numerous swollen mitochondria (arrows), almost always containing calcium phosphate inclusions along the inner aspect of the mitochondrial membrane, illustrates characteristic structural damage in the minor subset of cells. Bottom, Typical cell body after NMDA exposure exhibits swollen mitochondria with inclusions (arrows) similar to those seen in the minor subset of depolarized neurons (compare with middle panel). Scale bar (for all panels), $1 \mu \mathrm{m}$.

tracellular sodium/potassium distribution, strong depolarization induced at most minor changes in total sodium or potassium concentrations in both compartments of both subsets (Table 1), and in particular in the minor subset that exhibits high concentrations of calcium and damaged mitochondria (Fig. 5C,D). This observation is consistent with the relative cation permeabilities of NMDARs, which conduct $\mathrm{Na}^{+}$and $\mathrm{K}^{+}$as well as $\mathrm{Ca}^{2+}$, compared with VGCCs, which are highly $\mathrm{Ca}^{2+}$ selective. It further suggests that ATP depletion is likely to have limited impact on the depolarization-dependent component of neuronal injury, at least during the acute phase.

\section{Discussion}

In this study we have demonstrated that in the majority of cultured hippocampal or cortical neurons, even maximal VGCC
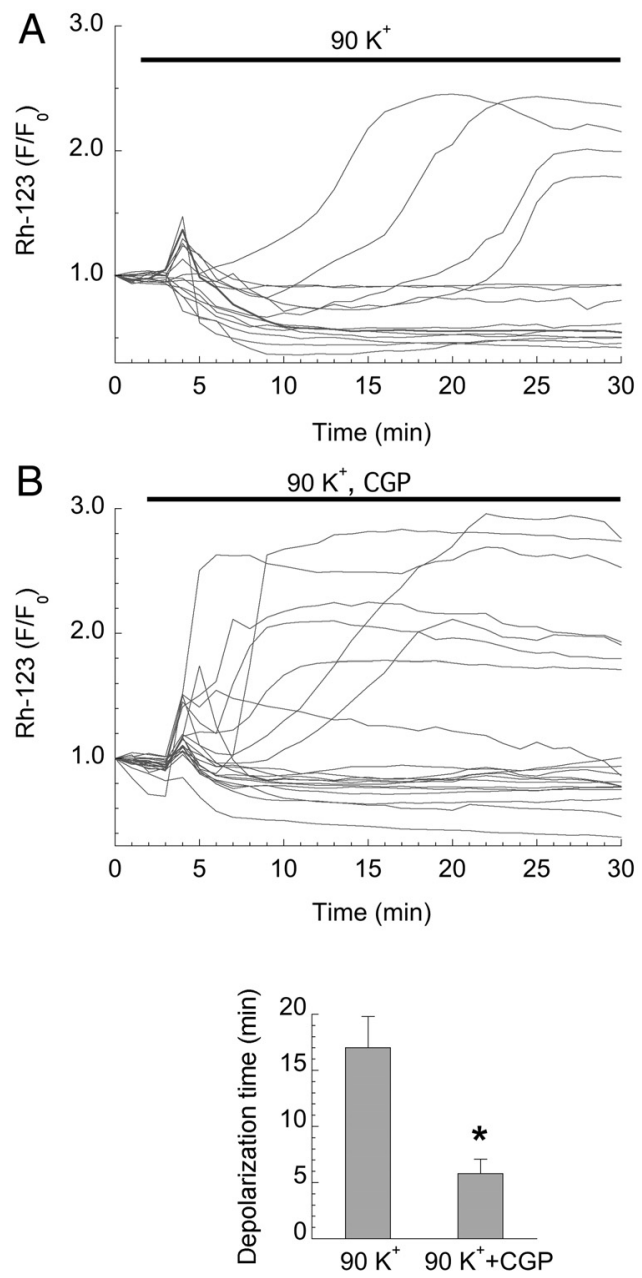

Figure 4. VGCC-mediated calcium overload and mitochondrial dysfunction. $A$, Time courses of Rh123 fluorescence $\left(F / F_{0}\right)$ in 28 DIV neurons reveal MMP depolarization in $\sim 30 \%$ of cells after $90 \mathrm{~mm} \mathrm{~K}{ }^{+}$depolarization (as described in Fig. 1). Depolarization is typically delayed by $10-20$ min. $B$, Enhancing mitochondrial calcium loading by blocking the mitochondrial $\mathrm{Na}^{+} /$ $\mathrm{Ca}^{2+}$ exchanger with (GP $37157(10 \mu \mathrm{M})$ significantly accelerates mitochondrial depolarization (bar graph, $p<0.01$ ), but does not change the fraction of depolarized cells, $35 \%$, which is consistent with the minor subset exhibiting structural damage. Traces from two replicate experiments.

activation (90 $\mathrm{mM} \mathrm{K}^{+}$plus Bay K 8644) induces limited calcium loading and minimal NO production. This outcome is comparable to that evoked by sublethal $(10 \mu \mathrm{M})$ NMDA exposure but much milder than the effects of toxic NMDA. Consequently, VGCC-mediated $\mathrm{Ca}^{2+}$ entry is minimally toxic. Moreover, alternative independent routes of $\mathrm{Ca}^{2+}$ entry such as reverse mode NCX, which produces intermediate levels of $\mathrm{Ca}^{2+}$ loading, or ionophore (ionomycin) exposure, which produces very high levels of $\mathrm{Ca}^{2+}$ loading, also induced death rates corresponding to the degree of calcium loading. The results recapitulate the now generally observed linkage between calcium loading and toxicity, thereby providing new insight into the longstanding puzzle as to why $\mathrm{Ca}^{2+}$ influx via VGCCs is so much less toxic than influx via NMDARs. In addition, we find that depolarization-induced calcium loading is highly variable from one neuron to the next, and thus there exists, at least in culture, a small but significant number of cells that exhibit strong calcium loading and attendant toxicity. In these cells, injury appears to follow the canonical excitotoxicity pathway involving mitochondrial calcium overload, structural damage, and subsequent dysfunction. 
Table 1. Effect of depolarization on elemental concentrations in cytoplasm and mitochondria of cultured 28 DIV hippocampal neurons

\begin{tabular}{|c|c|c|c|c|c|c|c|c|}
\hline \multirow[b]{2}{*}{ Row \# } & & \multirow[b]{2}{*}{$n$} & \multicolumn{6}{|c|}{ (mmol/kg dry weight) } \\
\hline & & & $\mathrm{Na}$ & $\mathrm{Mg}$ & $\mathrm{Cl}$ & $P$ & K & $\mathrm{Ca}$ \\
\hline & Cytoplasm & & & & & & & \\
\hline 1 & $\begin{array}{l}\text { Control } \\
90 \mathrm{~K}^{+}\end{array}$ & 45 & $23 \pm 4$ & $39 \pm 2$ & $63 \pm 5$ & $483 \pm 15$ & $511 \pm 16$ & $2.2 \pm 1.2$ \\
\hline 2 & Major subset $^{a}$ & 46 & $13 \pm 3$ & $25 \pm 2^{*}$ & $201 \pm 16^{*}$ & $335 \pm 18^{*}$ & $574 \pm 24$ & $3.8 \pm 1.2$ \\
\hline 3 & Minor subset ${ }^{b}$ & 35 & $42 \pm 5^{*}$ & $16 \pm 2^{*}$ & $239 \pm 16^{*}$ & $236 \pm 16^{*}$ & $469 \pm 25$ & $16.0 \pm 3.0^{*}$ \\
\hline 4 & $\begin{array}{c}\text { NMDA } \\
\text { Mitochondria }\end{array}$ & 47 & $644 \pm 73^{*}$ & $25 \pm 4^{*}$ & $484 \pm 55^{*}$ & $333 \pm 28^{*}$ & $67 \pm 12^{*}$ & $41.0 \pm 3.0^{*}$ \\
\hline 6 & Major subset ${ }^{a}$ & 49 & $6 \pm 2$ & $28 \pm 3$ & $81 \pm 8^{*}$ & $304 \pm 11$ & $313 \pm 17$ & $1.4 \pm 0.6$ \\
\hline 7 & Minor subset ${ }^{b}$ & 35 & $8 \pm 2$ & $53 \pm 5^{*}$ & $85 \pm 12^{*}$ & $643 \pm 48^{*}$ & $290 \pm 21$ & $650 \pm 95^{*}$ \\
\hline 8 & NMDA & 39 & $268 \pm 24^{*}$ & $43 \pm 5^{*}$ & $229 \pm 21^{*}$ & $869 \pm 58^{*}$ & $38 \pm 4^{*}$ & $1057 \pm 99^{*}$ \\
\hline
\end{tabular}

Cultures (28 DIV) were frozen immediately after 30 min exposure to high $\mathrm{K}^{+}\left(90 \mathrm{~mm} \mathrm{KCl}, 1 \mu \mathrm{m}\right.$ Bay K-8644 in $10 \mathrm{~mm} \mathrm{Ca}{ }^{2+} \mathrm{HBSS}$ ) in the presence of $20 \mu \mathrm{M}$ MK-801, $10 \mu \mathrm{m}$ CNQX, or to $100 \mu \mathrm{m} \mathrm{NMDA}$ in Mg-free HBSS in the presence of 10 $\mu \mathrm{M}$ nimodipine. Data are given as mean \pm SEM in $\mathrm{mmol} / \mathrm{kg}$ dry weight. The number of neurons analyzed was $10-15$ for each condition. $n$ is the number of analyses.

${ }^{a}$ Cells characterized by normal subcellular structure.

${ }^{b}$ Cells characterized by abundant structurally damaged mitochondria.

'Below detection limit.

*Different from control $(p<0.05$ ) for cytoplasm by one-way ANOVA with post hoc Dunnett's multiple-comparisons test, and for mitochondria by nonparametric Kruskal-Wallis rank ANOVA with post hoc Dunn's test for unbalanced data.
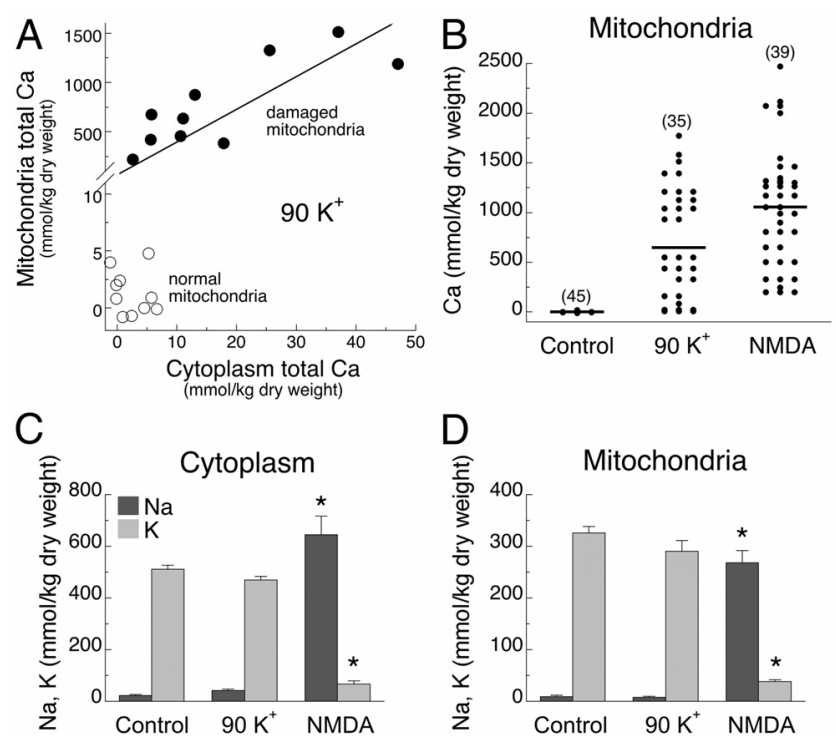

Figure 5. VGCC-mediated calcium loading and mitochondrial calcium accumulation. EPMA reveals that $90 \mathrm{~mm} \mathrm{~K}^{+}$exposure (as described in Fig. 1) induces calcium accumulation in the cytoplasm and mitochondria of the minor depolarization-responsive subset (see also Table 1, Rows 3 and 7) of 28 DIV neurons. $A$, Cell-by-cell correlation plot of mean concentrations of total calcium in cytoplasm versus mitochondria of individual cells from the minor subset characterized by damaged mitochondria (filled circles) and the dominant subset characterized by normal structure (open circles). Each data point represents the average of 3-5 measurements in the cytoplasm or 3-5 mitochondria from an individual neuron. Cytoplasmic and mitochondrial calcium concentration elevations in the minor subset are well correlated $\left(r^{2}=0.76\right)$. B, Calcium concentration in individual mitochondria of the minor subset are significantly elevated compared with control, with concentrations in most members of this group comparable to that induced by $100 \mu \mathrm{M}$ NMDA. Each data point represents a single measurement in an individual mitochondrion. The number of data points at each condition is given in parentheses. $\boldsymbol{C}, \boldsymbol{D}$, Intracellular concentrations of $\mathrm{Na}$ and $\mathrm{K}$ were not affected by $90 \mathrm{~mm} \mathrm{~K}{ }^{+}$depolarization, including in cells with elevated calcium, but were reversed after NMDA exposure $(p<0.001)$. EPMA data are means \pm SEM.

In view of the results just summarized, it is timely to reconsider the relationship between generalized $\mathrm{Ca}^{2+}$ loading and the known, selective toxicity of NMDAR-mediated $\mathrm{Ca}^{2+}$ entry, in particular emphasizing that present data offer a logical reconciliation of the source specificity and $\mathrm{Ca}^{2+}$ loading hypotheses. Specifically, our results indicate that, previous reports aside (Sattler et al., 1998), it is not physically possible, except in rare cases, to transport enough $\mathrm{Ca}^{2+}$ through VGCCs to $\mathrm{Ca}^{2+}$ load mitochondria to anywhere near toxic levels. In contrast, NMDARs are exceptionally toxic at least partly because they allow a much larger $\mathrm{Ca}^{2+}$ flux than VGCCs or, for that matter, any other plausible route of $\mathrm{Ca}^{2+}$ entry. However this view does not preclude additional, synergistic toxicity due to selective activation of specific signal transduction pathways. Perhaps the best example of such synergy might be the death mechanism-widely accepted and confirmed in our cells-that depends on nNOS/PSD coupling (Forder and Tymianski, 2009). It remains to be seen whether other death pathways can be explained within this framework. Examples include NMDAR-dependent toxicity selectively through extrasynaptic receptors (Stanika et al., 2009; Hardingham and Bading, 2010) or in cells lacking a PSD-like signaling complex (Soriano et al., 2008).

Because our approach facilitated single cell analysis, we were able to detect the small subset of vulnerable neurons that responded to depolarization with strong $\mathrm{Ca}^{2+}$ accumulation. Cells of this subset accumulated $\mathrm{Ca}^{2+}$-mainly through L-type VGCCs, since $\mathrm{Ca}^{2+}$ elevations were largely blocked by nimodipine-to concentrations that were two- to threefold higher than in the rest of the cells. This subset of neurons increased in size in older (28 DIV) cultures, more of which also exhibited higher L-type VGCC expression and larger $\mathrm{Ca}^{2+}$ currents in response to depolarization. The latter finding is consistent with earlier reports that have documented increased age-dependent VGCCmediated $\mathrm{Ca}^{2+}$ currents in parallel with increased VGCC expression in CA1 hippocampal neurons (Thibault and Landfield, 1996; Thibault et al., 2001).

The age-dependent increase in the fraction of depolarized cells showing high $\mathrm{Ca}^{2+}$ elevations and evident structural damage to mitochondria provided an opportunity to validate the proposition that when VGCC-mediated $\mathrm{Ca}^{2+}$ loading is excessive it will be toxic mainly via the mitochondrial dysfunction pathway. The logic is that the structural damage typical of NMDA-induced excitotoxic injury should be a distinguishing characteristic of those neurons that show large VGCC-dependent $\mathrm{Ca}^{2+}$ elevations, and that these two correlated characteristics should be more frequent in older cultures. Indeed, in the minor subset of 28 DIV depolarized cells characterized by swollen, structurally damaged mitochondria, the level of total mitochondrial cal- 
cium was many hundred times higher than in the nonresponsive population. Moreover, mitochondria were readily depolarized in a fraction of cells similar in size to the depolarization-induced death rate, viz., $\sim 30 \%$. These observations imply a pivotal role for mitochondrial calcium overload, a role that was demonstrated by inhibiting mitochondrial calcium uptake (with FCCP), which enhances cytosolic $\mathrm{Ca}^{2+}$ levels and by inhibiting mitochondrial $\mathrm{Ca}^{2+}$ release (with CGP 37157), which amplifies mitochondrial calcium overload and thus accelerates dysfunction. Our new results complement previous reports from ourselves and others demonstrating a significant, synergistic contribution of VGCC-mediated $\mathrm{Ca}^{2+}$ deregulation to NMDA-dependent excitotoxicity in older neurons (Brewer et al., 2007; Stanika et al., 2009), and are consistent with the emerging view that NMDARs and VGCCs are organized at postsynaptic membranes as independent signaling complexes (Di Biase et al., 2008). Increases in VGCC-mediated $\mathrm{Ca}^{2+}$ transients have also been implicated in $\mathrm{Ca}^{2+}$ dysregulation during brain aging and in age-related dementia (Thibault et al., 1998, 2007). The age dependence of channel expression raises, not for the first time, a cautionary note concerning the importance of accounting for the influence of the developmental program on any given laboratory's culture models of neurodegenerative conditions.

Beyond issues of brain aging, present findings are important because they strongly suggest that $\mathrm{Ca}^{2+}$ entering through routes other than NMDARs may play a role in calcium-dependent neurodegeneration. Without minimizing the primacy of glutamate receptors in the majority of brain injuries, it seems plausible that contributions from other pathways will have significant implications for devising therapies for a variety of neurodegenerative conditions in which mitochondrial $\mathrm{Ca}^{2+}$ homeostasis is compromised. In Parkinson's disease for example, dopaminergic neurons of the substantia nigra are selective vulnerable because pacemaking through L-type VGCCs marginalizes $\mathrm{Ca}^{2+}$ homeostasis and promotes mitochondriaderived oxidative stress (Guzman et al., 2010), while in neurons deficient in the Parkinson's-associated mitochondrial gene PINK-1, VGCC activation is sufficient to induce mitochondrial dysfunction and neurodegeneration (Gandhi et al., 2009). As another clinically important example, $\mathrm{Ca}^{2+}$-permeable AMPA receptors-whether endogenously expressed (Carriedo et al., 2000) or acquired by ischemia-exposed CNS neurons (Kwak and Weiss, 2006) - promote injury by mechanisms similar to NMDA exposure.

Most of the experiments described here were performed on primary hippocampal neurons in culture. Because much of the data pointing to route-specific injury mechanisms has been obtained on cortical preparations (Sattler et al., 1998, 1999), we repeated some of the most critical $\mathrm{Ca}^{2+}$ imaging experiments on cortical neurons. As the results were essentially similar for both cortical and hippocampal neurons, we find no evidence for tissue-specific differences in the calcium overload response.

Finally, by way of technical commentary, our $\mathrm{Ca}^{2+}$ imaging results, obtained using low-affinity $\mathrm{Ca}^{2+}$ probes, are generally consistent with several earlier studies that used similar $\mathrm{Ca}^{2+}$ indicators in neuronal preparations (Carriedo et al., 1998; Stout and Reynolds, 1999). Additional insight comes from direct EPMA measurements of total intracellular calcium. Beyond mere validation, EPMA measurements of total calcium in specific compartments - individual mitochondria being a prime example-when combined with fluorescence assays of free $\mathrm{Ca}^{2+}$, are especially informative for processes like calcium-dependent toxicity where knowing the total amount of calcium sequestered and its location is every bit as critical as free $\mathrm{Ca}^{2+}$ concentration changes. In this context, the EPMA approach (Fernandez-Segura and Warley, 2008) has significant advantages over other methods for assaying total calcium (Pivovarova and Andrews, 2010). Among these are the imaging capabilities of the electron microscope, which provide resolution well beyond the single-organelle level-and therefore certainty regarding the cell type and subcellular compartment analyzed while not being limited to ensemble averages - together with well documented, reliable quantitation routines and sub-millimolar sensitivity.

\section{References}

Aarts M, Liu Y, Liu L, Besshoh S, Arundine M, Gurd JW, Wang YT, Salter MW, Tymianski M (2002) Treatment of ischemic brain damage by perturbing NMDA receptor-PSD-95 protein interactions. Science 298:846-850

Abramov AY, Duchen MR (2008) Mechanisms underlying the loss of mitochondrial membrane potential in glutamate excitotoxicity. Biochim Biophys Acta 1777:953-964.

Bezprozvanny I (2009) Calcium signaling and neurodegenerative diseases. Trends Mol Med 15:89-100.

Brewer LD, Thibault O, Staton J, Thibault V, Rogers JT, Garcia-Ramos G, Kraner S, Landfield PW, Porter NM (2007) Increased vulnerability of hippocampal neurons with age in culture: temporal association with increases in NMDA receptor current, NR2A subunit expression and recruitment of L-type calcium channels. Brain Res 1151:20-31.

Carriedo SG, Yin HZ, Sensi SL, Weiss JH (1998) Rapid $\mathrm{Ca}^{2+}$ entry through $\mathrm{Ca}^{2+}$-permeable AMPA/Kainate channels triggers marked intracellular $\mathrm{Ca}^{2+}$ rises and consequent oxygen radical production. J Neurosci 18:7727-7738.

Carriedo SG, Sensi SL, Yin HZ, Weiss JH (2000) AMPA exposures induce mitochondrial $\mathrm{Ca}^{2+}$ overload and ROS generation in spinal motor neurons in vitro. J Neurosci 20:240-250.

Colledge M, Snyder EM, Crozier RA, Soderling JA, Jin Y, Langeberg LK, Lu H, Bear MF, Scott JD (2003) Ubiquitination regulates PSD-95 degradation and AMPA receptor surface expression. Neuron 40:595-607.

Di Biase V, Obermair GJ, Szabo Z, Altier C, Sanguesa J, Bourinet E, Flucher $\mathrm{BE}$ (2008) Stable membrane expression of postsynaptic $\mathrm{Ca}_{\mathrm{V}} 1.2$ calcium channel clusters is independent of interactions with AKAP79/150 and PDZ proteins. J Neurosci 28:13845-13855.

Fernandez-Segura E, Warley A (2008) Electron probe X-ray microanalysis for the study of cell physiology. Methods Cell Biol 88:19-43.

Forder JP, Tymianski M (2009) Postsynaptic mechanisms of excitotoxicity: Involvement of postsynaptic density proteins, radicals, and oxidant molecules. Neuroscience 158:293-300.

Gandhi S, Wood-Kaczmar A, Yao Z, Plun-Favreau H, Deas E, Klupsch K, Downward J, Latchman DS, Tabrizi SJ, Wood NW, Duchen MR, Abramov AY (2009) PINK1-associated Parkinson's disease is caused by neuronal vulnerability to calcium-induced cell death. Mol Cell 33:627-638.

Greve MW, Zink BJ (2009) Pathophysiology of traumatic brain injury. Mt Sinai J Med 76:97-104.

Grynkiewicz G, Poenie M, Tsien RY (1985) A new generation of $\mathrm{Ca}^{2+}$ indicators with greatly improved fluorescence properties. J Biol Chem 260:3440-3450.

Guzman JN, Sanchez-Padilla J, Wokosin D, Kondapalli J, Ilijic E, Schumacker PT, Surmeier DJ (2010) Oxidant stress evoked by pacemaking in dopaminergic neurons is attenuated by DJ-1. Nature 468:696-700.

Hardingham GE, Bading H (2010) Synaptic versus extrasynaptic NMDA receptor signalling: implications for neurodegenerative disorders. Nat Rev Neurosci 11:682-696.

Hardingham GE, Fukunaga Y, Bading H (2002) Extrasynaptic NMDARs oppose synaptic NMDARs by triggering CREB shut-off and cell death pathways. Nat Neurosci 5:405-414.

Hartley DM, Kurth MC, Bjerkness L, Weiss JH, Choi DW (1993) Glutamate receptor-induced ${ }^{45} \mathrm{Ca}^{2+}$ accumulation in cortical cell culture correlates with subsequent neuronal degeneration. J Neurosci 13:1993-2000.

Hyrc K, Handran SD, Rothman SM, Goldberg MP (1997) Ionized intracellular calcium concentration predicts excitotoxic neuronal death: observations with low-affinity fluorescent calcium indicators. J Neurosci 17:6669-6677.

Kiedrowski L, Czyz A, Baranauskas G, Li XF, Lytton J (2004) Differential contribution of plasmalemmal $\mathrm{Na} / \mathrm{Ca}$ exchange isoforms to sodiumdependent calcium influx and NMDA excitotoxicity in depolarized neurons. J Neurochem 90:117-128. 
Kristian T, Pivovarova NB, Fiskum G, Andrews SB (2007) Calcium-induced precipitate formation in brain mitochondria: composition, calcium capacity, and retention. J Neurochem 102:1346-1356.

Kwak S, Weiss JH (2006) Calcium-permeable AMPA channels in neurodegenerative disease and ischemia. Curr Opin Neurobiol 16:281-287.

Li V, Brustovetsky T, Brustovetsky N (2009) Role of cyclophilin D-dependent mitochondrial permeability transition in glutamateinduced calcium deregulation and excitotoxic neuronal death. Exp Neurol 218:171-182.

Marks JD, Boriboun C, Wang J (2005) Mitochondrial nitric oxide mediates decreased vulnerability of hippocampal neurons from immature animals to NMDA. J Neurosci 25:6561-6575.

Nicholls DG (2008) Oxidative stress and energy crises in neuronal dysfunction. Ann N Y Acad Sci 1147:53-60.

Nicholls DG (2009) Mitochondrial calcium function and dysfunction in the central nervous system. Biochim Biophys Acta 1787:1416-1424.

Pivovarova NB, Andrews SB (2010) Calcium-dependent mitochondrial function and dysfunction in neurons. FEBS J 277:3622-3636.

Pivovarova NB, Hongpaisan J, Andrews SB, Friel DD (1999) Depolarizationinduced mitochondrial $\mathrm{Ca}$ accumulation in sympathetic neurons: spatial and temporal characteristics. J Neurosci 19:6372-6384.

Pivovarova NB, Nguyen HV, Winters CA, Brantner CA, Smith CL, Andrews SB (2004) Excitotoxic calcium overload in a subpopulation of mitochondria triggers delayed death in hippocampal neurons. J Neurosci 24:5611-5622.

Pivovarova NB, Stanika RI, Watts CA, Brantner CA, Smith CL, Andrews SB (2008) Reduced calcium-dependent mitochondrial damage underlies the reduced vulnerability of excitotoxicity-tolerant hippocampal neurons. J Neurochem 104:1686-1699.

Sattler R, Charlton MP, Hafner M, Tymianski M (1998) Distinct influx pathways, not calcium load, determine neuronal vulnerability to calcium neurotoxicity. J Neurochem 71:2349-2364.

Sattler R, Xiong Z, Lu WY, Hafner M, MacDonald JF, Tymianski M (1999) Specific coupling of NMDA receptor activation to nitric oxide neurotoxicity by PSD-95 protein. Science 284:1845-1848.

Schinder AF, Olson EC, Spitzer NC, Montal M (1996) Mitochondrial dysfunction is a primary event in glutamate neurotoxicity. J Neurosci $16: 6125-6133$.
Soriano FX, Martel MA, Papadia S, Vaslin A, Baxter P, Rickman C, Forder J, Tymianski M, Duncan R, Aarts M, Clarke P, Wyllie DJ, Hardingham GE (2008) Specific targeting of pro-death NMDA receptor signals with differing reliance on the NR2B PDZ ligand. J Neurosci 28:10696-10710.

Stanika RI, Pivovarova NB, Brantner CA, Watts CA, Winters CA, Andrews SB (2009) Coupling diverse routes of calcium entry to mitochondrial dysfunction and glutamate excitotoxicity. Proc Natl Acad Sci U S A 106:9854-9859.

Stout AK, Reynolds IJ (1999) High-affinity calcium indicators underestimate increases in intracellular calcium concentrations associated with excitotoxic glutamate stimulations. Neuroscience 89:91-100.

Stout AK, Raphael HM, Kanterewicz BI, Klann E, Reynolds IJ (1998) Glutamate-induced neuron death requires mitochondrial calcium uptake. Nat Neurosci 1:366-373.

Szydlowska K, Tymianski M (2010) Calcium, ischemia and excitotoxicity. Cell Calcium 47:122-129.

Thibault O, Landfield PW (1996) Increase in single L-type calcium channels in hippocampal neurons during aging. Science 272:1017-1020.

Thibault O, Porter NM, Chen KC, Blalock EM, Kaminker PG, Clodfelter GV, Brewer LD, Landfield PW (1998) Calcium dysregulation in neuronal aging and Alzheimer's disease: history and new directions. Cell Calcium 24:417-433.

Thibault O, Hadley R, Landfield PW (2001) Elevated postsynaptic $\left[\mathrm{Ca}^{2+}\right]_{i}$ and L-type calcium channel activity in aged hippocampal neurons: relationship to impaired synaptic plasticity. J Neurosci 21:9744-9756.

Thibault O, Gant JC, Landfield PW (2007) Expansion of the calcium hypothesis of brain aging and Alzheimer's disease: minding the store. Aging Cell 6:307-317.

Tymianski M (2009) International Stroke Conference 2009. Translation of high impact targets into clinical trials. February 17-20, 2009, San Diego, CA. IDrugs 12:217-219.

Tymianski M, Charlton MP, Carlen PL, Tator CH (1993) Source specificity of early calcium neurotoxicity in cultured embryonic spinal neurons. J Neurosci 13:2085-2104.

Vergun O, Keelan J, Khodorov BI, Duchen MR (1999) Glutamate-induced mitochondrial depolarisation and perturbation of calcium homeostasis in cultured rat hippocampal neurones. J Physiol 519:451-466. 